\title{
Changes of Heart Autonomic Regulation as Predictors of Tension Type Headache
}

\author{
DOI: $10.17691 / \mathrm{stm} 2019.11 .1 .19$
}

Received December 3, 2018

K.A. Mashkovich, Tutor, Department of Neurology, Neurosurgery, and Medical Genetics;

V.N. Grigoryeva, MD, DSc, Professor, Head of the Department of Neurology, Neurosurgery, and Medical Genetics

Privolzhsky Research Medical University, 10/1 Minin and Pozharsky Square, Nizhny Novgorod, 603005, Russia

The aim of the study was to investigate the dynamics of heart rate variability (HRV) and its relation to the daily physical activity and emotional stress level in tension type headache (TTH) patients in order to identify the objective correlates of headache.

Materials and Methods. 166 medical students have been examined: 60 students with frequent episodic TTH (FETTH), 28 students with chronic TTH (CTTH), 18 students with migraine combined with FETTH, and 60 headache-free persons. The examination included clinical neurological and somatic examination, assessment of daily physical activity and emotional stress level, as well as investigation of the autonomic nervous system using HRV at rest and in the process of students' daily activity.

Results and Discussion. In young people with FETTH and CTTH the parameters of HRV differ from headache-free persons. These changes indicate the increase of the sympathetic and decrease of the parasympathetic activity.

The young people with CTTH have flat daytime profiles of HRV parameters.

The decrease of HRV and the flattening of daytime profiles of HRV parameters are associated with high level of emotional stress and hypodynamia. Headache may have some independent influence on HRV parameters, but this impact is less than impact of emotional stress and hypodynamia.

Conclusion. The characteristics of HRV dynamics during the day (daytime profiles) may be used as objective neurophysiological indicators of high emotional stress and hypodynamia which are the factors of TTH development and chronicity.

Key words: heart rate variability; tension type headache; emotional stress; daily physical activity.

\section{Introduction}

Tension type headache (TTH) is a widespread pathology [1]. Optimal approaches to the management of this disorder require understanding of the mechanisms of its development.

The role of the autonomic dysfunction in TTH pathogenesis is still unclear [2]. The monitoring of heart rate variability (HRV) in the process of human daily activity is important for understanding of TTH pathogenesis [3]. However, such investigations are single and are used to compare daytime and nocturnal indices of HRV in chronic pain syndromes and migraine $[4,5]$.

The data about correlation between the daytime HRV dynamics and TTH are very important to verify the pathogenetic subtypes of TTH and the autonomic correlates of headache. It also might be useful for identification of the essential risk factors of TTH development and chronicity such as daily stress and hypodynamia (which also leads to autonomic dysregulation) [1].

The aim of the study was to investigate the dynamics of heart rate variability and its relation to the daily physical activity and emotional stress level in tension type headache patients in order to identify the objective correlates of headache.

\section{Materials and Methods}

166 students of the $5^{\text {th }}$ and $6^{\text {th }}$ courses of the Medical University have been examined (137 women, 29 men, average age $22.4 \pm 3.0$ years). Four groups were formed. The groups consisted of 60 headache-free students (11 men, 49 women); 60 people (11 men, 49 women) with frequent episodic TTH (FETTH); 28 students (5 men, 23 women) with chronic TTH (CTTH); 18 students (2 men, 16 women) with migraine combined with FETTH (migraine + FETTH), respectively.

The study complies with the Declaration of Helsinki (2013) and approved by the Ethics Committee of Privolzhsky Research Medical University. Informed consent was obtained from every patient.

The study was carried out on weekdays. The following methods were used.

Clinical neurological examination. Diagnosis of the headache type was made according to the criteria of the International Classification of Headache Disorders (ICHD) [6].

5 min ECG recording at rest with time and frequency

Corresponding author: Vera N. Grigoryeva, e-mail: vrgr@yandex.ru 
domain analyses of HRV using VNS-Micro vegetotester (Neuro-soft, Russia).

Monitoring of HRV for 12-hour period (from 8 a.m. till 8 p.m.) with computation of average daily time domain and frequency domain of HRV parameters and the analysis of the dynamics of these parameters. A miniature Zephyr ${ }^{\mathrm{TM}} \mathrm{HxMonitor}$ sensor (registered by Zephyr Technology Corporation in 2010 as a device for fitnessmonitoring of heart rate) was attached to the body by elastic chest belt. R-R interval data were transmitted from the sensor via the radio signal according to the Bluetooth SPP protocol to the student's smartphone. The smartphone using a HR-Reader program [7] acquired, stored and transmitted the data to the internet server "Web service for visualization and storing of heart rate measurements" [8]. The sequences of R-R intervals were filtered and mathematically processed on this server.

Assessment of the emotional stress level using the following scales and questionnaires: the Hospital Anxiety and Depression Scale (HADS) with identification of anxiety (AL) and depression (DL) levels [9]; Mini-Mult test [10]; the Psychological Stress Scale (PSM-25) [11]. All examined students were divided by the cluster analysis into two groups depending on the following data: $A L$ and $D L ;$ values of the second and seventh scales of Mini-Mult test; integral index of PSM-25 questionnaire. Students of the first cluster had low level of stress, while student of the second cluster had high level of stress.

Student's physical activity level was assessed by the calculation of the step number traveled from 8 a.m. till 8 p.m. with a use of a three-axis accelerometer iHealth Wireless activity (iHealth Lab Inc., USA). This accelerometer was attached to the wrist. The general level of physical activity was assessed by the Physical Activity Level Scale [12]. Hypodynamia was diagnosed if the results of the scale assessment and questioning revealed that medium intensive physical activity occupied less than $150 \mathrm{~min} /$ week or highly intensive physical activity occupied less than $75 \mathrm{~min} /$ week.

The results were statistically analyzed using Statistica 6.0 software. Comparison of two samples was done using Student's unpaired t-test for independent groups and paired Student's t-test for related groups when analyzing variables following normal distribution. To compare the means in the three and more independent samples from the population with a normal distribution one-way analysis of variance (ANOVA) was applied. To create various groups of people with similar characteristics, the technique of k-means with agglomerative hierarchical clustering was used. In order to compare the daily dynamic of parameters in different student's groups, two-way repeated measure analysis of variance was performed with one intragroup (a day period) and one intergroup (belonging to a group) factor (repeated measure ANOVA). The Spearman's correlation analysis was used to study the association between random values.

\section{Results and Discussion}

The students with episodic as well as with chronic TTH in comparison with the students without headache had statistically significantly lower standard deviation of $\mathrm{N}-\mathrm{N}$ intervals (SDNN, ms), total power of the spectrum (TP, $\mathrm{ms}^{2} / \mathrm{Hz}$ ), the power in the high frequency range $\left(\mathrm{HF}, \mathrm{ms}^{2} / \mathrm{Hz}\right)$ and the percentage of a high frequency component in the total spectrum power (\%HF). The students with headache also had higher sympathovagal balance coefficient (LF/HF) than the headache-free students. It implied increase of sympathetic nervous system activity in TTH.

This data contradict the results of some authors who did not find any differences between HRV frequency domain parameters in TTH patients and healthy people [13]. At the same time, our findings confirm the data of other authors [2, 14, 15]. Thus, Yakupova [15] revealed sympathecotonia in $74 \%$ of patients with CTTH analyzing the HRV parameters at rest.

One of the causes for increase of sympathetic activity and decrease of parasympathetic activity may be an emotional stress associated with TTH $[16,17]$. The average emotional stress level (according to the scores of the questionnaires) was statistically higher in TTH students comparing with headache-free students. The percentage of students with the high level of stress was higher in students with CTTH (21 of 28 or $75 \%$ ), FETTH (32 of 60 or $53 \%$ ) and "migraine + FETTH" (15 of 18 or $83 \%$ ) compared with the headache-free students (11 of 60 or $18.3 \%$ ), $p=0.0000$ for all compared groups. This data implied the mediating role of stress in reducing of HRV.

The decrease of average daily physical activity (hypodinamia) was statistically more prominent in the TTH students compared to those without headache. The percentage of people with hypodinamia in the groups of students with "migraine + FETTH" (17 of 18 or 94\%), CTTH (20 of 28 or $71.4 \%$ ) as well with FETTH (39 of 60 or $65 \%$ ) was statistically significantly higher than in the group without cephalgia (16 of 60 or $26.6 \%$ ); $p=0.0000$. These data indirectly indicate that low physical activity may contribute to the reduction of the HRV parameters at rest. The fact that the decrease of everyday physical activity results in the reduction of HRV is described by some authors [18].

The results of 12-hour monitoring demonstrated the decrease of average daily HRV in the students with FETTH and CTTH compared to headache-free students. The results imply the increase of sympathetic and decrease of parasympathetic activity both in FETTH and CTTH.

The most of average daily HRV parameters statistically significantly negatively correlated with the emotional stress level and positively with the level of the daily physical activity and the number of steps made by students during a day.

In order to assess the dynamics of HRV parameters 
from 8 a.m. till 8 p.m., these parameters were averaged for each of three 4-hour periods of the daytime. So, SDNNi of the first third of the day $\left(\mathrm{SDNNi}_{8-12}\right)$ was calculated as a mean SDNN for all 5-min recording segments from 8 to 12 a.m. Similarly were calculated SDNNi ${ }_{12-16}$ and $\mathrm{SDNNi}_{16-20}$. The sequence of SDNNi for three thirds of the day was named here as "a daytime SDNNi profile".

Two-way repeated measure analysis of variance revealed the differences in the daytime SDNNi profiles for headache-free students, students with FETTH, CTTH, and "migraine + FETTH" students, $p=0.038$ (Figure 1). SDNNi daytime profiles of TTH students were lower than those ones of headache-free students. Additionally, the daytime SDNNi profile in CTTH had another shape, than the profile of headache-free students.

The differences between daytime profiles of headache-free students and students headache were also present for such HRV frequency domain parameters as TP $\left(\mathrm{ms}^{2}\right), \mathrm{p}=0.0000 ; \operatorname{VLF}\left(\mathrm{ms}^{2}\right), \mathrm{p}=0.01$; LF $\left(\mathrm{ms}^{2}\right)$, $\mathrm{p}=0.0000 ; \mathrm{HF}\left(\mathrm{ms}^{2}\right), \mathrm{p}=0.0000$.

Taking into account that the CTTH students had higher levels of emotional stress and hypodynamia, it would be logically to suggest that the same factors mediate the differences of the daytime SDNNi profiles in the CTTH students in comprasion with the other students. This assumption agrees with the data of Verkuil et al. [19] who studied the HRV parameters during three different day periods and established that the HRV parameters in the people with chronic emotional stress are lower than in those without stress and less variable over the daytime.

To clarify this assumption, we additionally analyzed the daytime SDNNi profiles in three categories of students:

category 1 - with low emotional stress without hypodynamia $(n=51 ; 14$ of them with TTH);

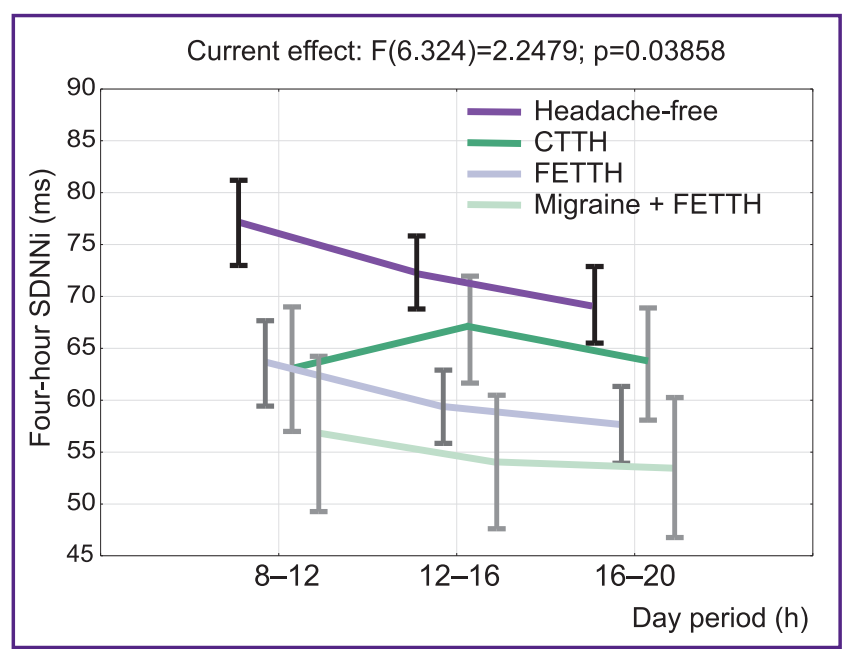

Figure 1. The daytime SDNNi profiles in the subgroups of headache-free students, CTTH, FETTH, and migraine in combination with FETTH category 2 - with high emotional stress or with hypodynamia ( $n=59 ; 40$ of them with TTH);

category 3 - with high emotional stress and hypodynamia ( $n=56 ; 52$ of them with TTH).

The comparison of the daytime SDNNi profiles in the students of these categories revealed statistically significant differences $(p=0.0000)$. The SDNNi profiles in persons with high emotional stress and hypodynamia were lower and flatter (Figure 2).

Considering these data, objective criteria for high emotional stress combined with hypodynamia was proposed. These criteria were as follows: either a low daytime SDNNi profile $\left(\mathrm{SDNNi}_{8-12}, \mathrm{SDNNi}_{12-16}\right.$, $\mathrm{SDNNi}_{16-20}$ are less than $70 \mathrm{~ms}$ ) or the flattened daytime SDNNi profile (the difference between the adjacent 4-hour SDNNi is less than $10 \mathrm{~ms}$ ). The sensitivity and specificity of these criteria were 86 and $65 \%$, respectively.

The neurophysical objectivization of emotional stress and hypodynamia is important because they are the risk factors of TTH and a number of other "diseases of civilization" [20].

The flattening of the daytime SDNNi profile in CTTH students was associated with increased prevalence of emotional stress and hypodynamia (61\%) compared with headache-free students $(7 \% ; p=0.0000)$ and FETTH students (35\%; $p=0.02)$. It additionally supports the hypothesis that the flattening of the daytime SDNNi profile in CTTH students is mainly explained by the combination of the appropriate factors.

On the other hand, pain may also change the autonomic regulation the fact which has been proved by Adlan et al. [21]. So we compared the profiles of SDNNi and the average daytime SDNNi in those headache-free students and TTH students who had the same levels of emotional stress and hypodynamia. Headache-free students had on average higher mean daytime SDNNi

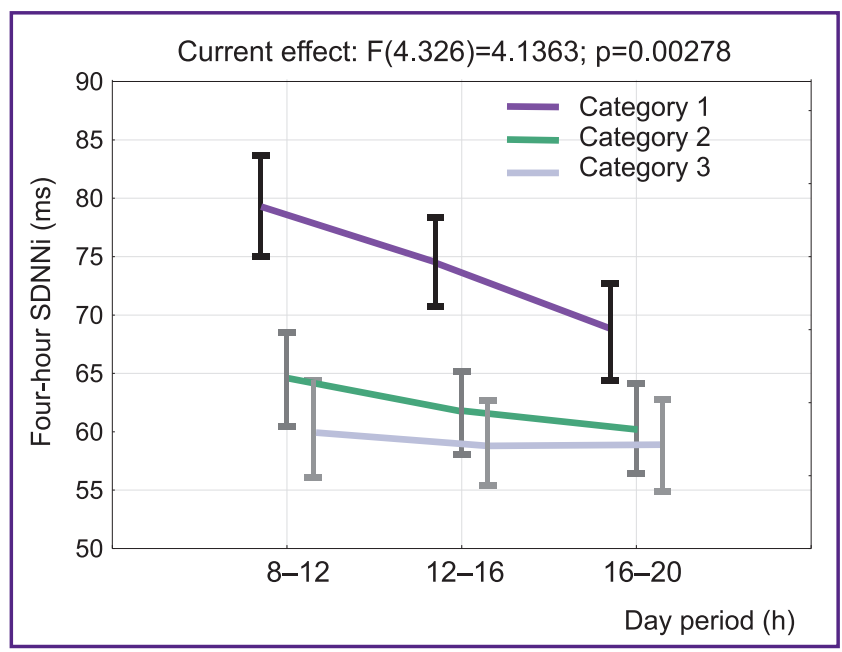

Figure 2. The daytime SDNNi profiles in the subgroups of students with different intensity of the emotional stress and physical activity 
$(p=0.03), \operatorname{VLF}(p=0.01), \operatorname{LF}(p=0.03), \operatorname{HF}(p=0.0000)$, TP $(p=0.0000)$ than TTH students. As for the shape of the daytime SDNNi profiles, the difference in the mentioned groups did not reach statistical significance.

Thus, the flattering of daily HRV profiles and the changes of average HRV parameters indicating increase the sympathetic activity in TTH students are explained mostly by high level of emotional stress and hypodynamia and only partially by pain itself.

\section{Conclusion}

In young people with FETTH and CTTH the parameters of HRV differ from headache-free persons. These changes indicate the increase of the sympathetic and decrease of the parasympathetic activity.

The young people with CTTH have flat daytime profiles of HRV parameters.

The decrease of HRV and the flattening of daytime profiles of HRV parameters are associated with high level of emotional stress and hypodynamia. Headache may have some independent influence on HRV parameters, but this impact is less than the impact of emotional stress and hypodynamia.

Acknowledgement. The authors thank S.A. Polevaya for teaching them the cardiac rhythm telemetry.

Study funding and conflicts of interest. The work was not supported by any financial sources and there are no conflicts of interest related to this study.

\section{References}

1. Akhmadeeva L.R., Azimova Yu.E., Karakulova Yu.V., Lebedeva E.R., Naprienko M.V., Osipova V.V., Rachin A.P., Sergeev A.V., Skorobogatykh K.V., Tabeeva G.R., Filatova E.G. Clinical recommendations on diagnosis and treatment of tension headache. Russkij medicinskij zurnal 2016; 7: 411-419.

2. Gass J.J., Glaros A.G. Autonomic dysregulation in headache patients. Appl Psychophysiol Biofeedback 2013; 38(4): 257-263, https://doi.org/10.1007/s10484-013-9231-8.

3. Kim D., Seo Y., Cho J., Cho C.H. Detection of subjects with higher self-reporting stress scores using heart rate variability patterns during the day. Conf Proc IEEE Eng Med Biol Soc 2008; 2008: 682-685, https://doi.org/10.1109/ iembs.2008.4649244.

4. Koenig J.y Clamor A., Loerbroks A., Jarczok M.N., Fischer J.E., Thayer J.F Only by the night: a closer look at parasympathetic nervous system dysregulation in chronic pain. Pain Pract 2017; 17(4): 568-569, https://doi.org/10.1111/ papr. 12564

5. Tabata M., Takeshima T., Burioka N., Nomura T., Ishizaki K., Mori N., Kowa H. Nakashima K. Cosinor analysis of heart rate variability in ambulatory migraineurs. Headache 2000; 40(6): 457-463, https://doi.org/10.1046/. 1526-4610. 2000.00068.x.

6. The International Classification of Headache Disorders. Cephalalgia 2013; 33(9): 629-808, https:/doi org/10.1177/0333102413485658.

7. Kozhevnikov V.V., Polevaya S.A., Shishalov I.S.
Bakhchina A.V. Mobile HR-meter (HR-meter). Certificate of state registration of computer programs 2014618634. 2014.

8. Eremin E.V., Kozhevnikov V.V., Polevaya S.A., Bakhchina A.V. Web service for visualization and storing of heart rate measurements. Certificate of state registration of databases 2014621202. 2014.

9. Zigmond A.S., Snaith R.P. The hospital anxiety and depression scale. Acta Psychiatr Scand 1983; 67(6): 361-370, https://doi.org/10.1111/j.1600-0447.1983.tb09716.x.

10. Epanchintseva E.M., Semke V.Ya., Garganeeva N.P., Zaytsev V.P. A variant of the psychological Mini-Mult test. Psikhologicheskiy zhurnal 1981; 3: 118-123.

11. Vodop'yanova N.E., Starchenkova E.S. Sindrom vygoraniya: diagnostika i profilaktika [Burnout syndrome: diagnosis and prevention]. Saint Petersburg: Izdatel'stvo Yurayt; 2005.

12. Jackson A.S., Blair S.N., Mahar M.T., Wier L.T., Ross R.M., Stuteville J.E. Prediction of functional aerobic capacity without exercise testing. Medicine \& Science in Sports \& Exercise 1990; 22(6): 863, https://doi.org/10.1249/00005768199012000-00021.

13. Takahiro Maruta S.E. Spectral analyses of heart rate variability by acceleration plethysmography for diagnostic support of migraine: clinical research. J Neurol Disord 2015; 3(2), https://doi.org/10.4172/2329-6895.1000229.

14. Akarachkova E.S. Rol' vegetativnoy nervnoy sistemy $v$ patogeneze golovnoy boli napryazheniya. Avtoref. dis. ... dokt. med. nauk [The role of the vegetative nervous system in the pathogenesis of tension headache. DSc Thesis]. Moscow; 2012.

15. Yakupova A.A. Khronicheskaya golovnaya bol' napryazheniya (kliniko-neyrofiziologicheskaya kharakteristika, mekhanizmy, lechenie). Avtoref. dis. ... dokt. med. nauk [Chronic tension headache (clinical and neurophysiological characteristic mechanisms, treatment). DSc Thesis]. Kazan; 2011.

16. Kim H.-G., Cheon E.-J., Bai D.-S., Lee Y.H., Koo B.-H. Stress and heart rate variability: a meta-analysis and review of the literature. Psychiatry Investig 2018; 15(3): 235-245, https:// doi.org/10.30773/pi.2017.08.17.

17. Won E., Kim Y.-K. Stress, the autonomic nervous system, and the immune-kynurenine pathway in the etiology of depression. Curr Neuropharmacol 2016; 14(7): 665-673, https://doi.org/10.2174/1570159x14666151208113006.

18. Prinsloo G.E., Rauch H.G.L., Derman W.E. A brief review and clinical application of heart rate variability biofeedback in sports, exercise, and rehabilitation medicine. Phys Sportsmed 2014; 42(2): 88-99, https://doi.org/10.3810/ psm.2014.05.2061.

19. Verkuil B., Brosschot J.F., Tollenaar M.S., Lane R.D., Thayer J.F. Prolonged non-metabolic heart rate variability reduction as a physiological marker of psychological stress in daily life. Ann Behav Med 2016; 50(5): 704-714, https://doi. org/10.1007/s12160-016-9795-7.

20. Sanlier N., Pehlivan M., Sabuncular G., Bakan S., Isguzar $Y$. Determining the relationship between body mass index, healthy lifestyle behaviors and social appearance anxiety. Ecol Food Nutr 2017; 57(2): 124-139, https://doi.org/1 0.1080/03670244.2017.1419343.

21. Adlan A.M., Veldhuijzen van Zanten J.J.C.S., Lip G.Y.H., Paton J.F.R., Kitas G.D., Fisher J.P. Cardiovascular autonomic regulation, inflammation and pain in rheumatoid arthritis Auton Neurosci 2017; 208: 137-145, https://doi.org/10.1016/j. autneu.2017.09.003. 